\title{
Winter chill of Geneva warmed by the WHO Executive Board
}

\author{
Ala Alwan'
}

The winter chill of Geneva is warmed in the last week of January every year by the meeting of the WHO Executive Board, which gathers to follow up on decisions of the World Health Assembly and provide guidance and direction to the WHO Secretariat. This year, the Board was faced with a record number of agenda items. Some of these were crucial to the current global public health situation and others to the future of global health and to WHO itself.

The Executive Board held a special session on the Ebola emergency. The discussions took place against the backdrop of the most recent data showing a reduction in new cases. This good news was welcomed, but it also highlighted the impact of the surge in resources put in place to respond to the outbreak, resources that are not ordinarily available, as has been highlighted by recent articles in the global press. The Board urged WHO to maintain the positive impact of the current response, including the assignment of a Special Representative for coordination and response. It requested an interim assessment of WHO's outbreak response and drew attention to areas where it felt $\mathrm{WHO}$ capacity needed strengthening. The Board was concerned also to recognize the selfless contribution of health workers, and the need for support for survivors, their families and children orphaned by the outbreak.

In its discussion on progress in implementation of the International Health Regulations (IHR 2005), a number of Board Members from our
Region noted the discrepancies shown up by the recent country assessments for Ebola readiness conducted in the Region, and the self-assessments conducted by Member States of readiness to implement the IHR. The MERS$\mathrm{CoV}$ outbreaks in our Region, as well as the Ebola outbreaks, underscore the insufficiency of current capacities to deal with global outbreak emergencies and highlight further the need for countries to make IHR implementation a national priority.

With the good news that no new cases of polio had been reported in Africa for the past 6 months, the continuing presence of polio in our Region was brought under the spotlight. Through the regional members of the Board, Member States of the Region reiterated their commitment to stopping transmission and to supporting the national efforts being made in Afghanistan and Pakistan. Pakistan, in particular, is affected by intense transmission of the virus, accounting for $85 \%$ of all new cases in 2014, and the virus continues to spread beyond its borders. The Board was informed that Pakistan is implementing an emergency plan. This remains a regional and global challenge that requires continuing political, civil society and religious leadership.

Noncommunicable diseases were brought into the spotlight again as Board Members discussed how to take the work forward on implementing the 2011 political declaration of the United Nations General Assembly on prevention and control of noncommunicable diseases. The regional Board members, following up on the request of the Regional Committee in October 2014, were keen to push for process indicators by which Member States could measure their progress towards implementation and against which WHO could report to the General Assembly. Other members were less eager to add to existing agreements. After much lively debate, compromise was reached and the Board requested the Director-General to publish a technical note, in the next few months, on how she will report, in 2017, to the UN General Assembly on the national commitments made in 2011 and 2014, using existing survey tools and taking into account existing indicators at global and regional levels.

The Board also considered the future of WHO itself and the drive for reform. One of the key strategic directions for our work in the Region over the past three years has been to strengthen and streamline management, including moving more resources to country level, and thus provide more efficient and effective support to Member States. I was able to assure members of the Board that in the Region we have put in place managerial measures to improve transparency, improve compliance with standard procedures and mitigate risks to operations. Many of the measures put in place have already brought positive results. Board members urged WHO to implement similar measures across all regions, and we will continue to improve and expand our efforts in this important area. 
Also in the context of reform, the Board discussed several issues that will have impact on the work of WHO in general and its programmes at country level in the years to come. Of particular note were the items on rotation and mobility of WHO staff, the distribution of funds across the three levels of WHO (termed 'strategic budget space allocation'), and the programme budget for 2016/2017. While rotation and mobility of the WHO workforce was welcomed by the Board, the other two items were extensively debated. The Board requested the Working Group on Strategic Budget Space Allocation to continue its work and to report back at its next session on the specific issue of technical cooperation at country level. It entrusted WHO with additional work on the proposed programme budget
2016/2017 before presenting it to the World Health Assembly for endorsement in May 2015. It is my view that the success of reform will depend, to a great extent, on how WHO can reinforce its country presence and strengthen technical support to countries.

The WHO Executive Board has 34 members, who serve 3 year terms, and represent the six regions. Member States who are not currently members of the Board may participate in the meeting without vote. It has been heartening in recent years to see ever more interest and active participation from Member States of the Region who are not Board members. In addition to the five current Board Members from the Region, 10 Member States sent delegations this year, as well as Palestine which has Observer status. Regional participants were vocal in the discussions and in supporting crucial decisions that will affect WHO's work in the Region.

One of the most interesting aspects of governance forums such as the WHO Executive Board and the World Health Assembly is the interaction and collaboration between ministry of health experts and diplomats, as Member States engage in health diplomacy and negotiation. This year, we were able to demonstrate the value of this to a new generation of regional health leaders who were attending the first Leadership for Health Programme and who had the chance to attend the Executive Board meeting and observe one of WHO's governing bodies in action. I hope we will see some of them representing Member States on the Board in future years. 